\title{
Additive manufacturing of hydroxyapatite bioceramic scaffolds: Dispersion, digital light processing, sintering, mechanical properties, and biocompatibility
}

\author{
Chengwei $\mathrm{FENG}^{a}$, Keqiang $\mathrm{ZHANG}^{a}$, Rujie $\mathrm{HE}^{a,{ }^{*}}$, Guojiao $\mathrm{DING}^{a}$, \\ Min XIA ${ }^{b}$, Xinxin $\mathrm{JIN}^{c}$, Chen $\mathrm{XIE}^{d, *}$ \\ ${ }^{a}$ Institute of Advanced Structure Technology, Beijing Institute of Technology, Beijing 100081, China \\ ${ }^{b}$ School of Materials Science and Engineering, Beijing Institute of Technology, Beijing 100081, China \\ ${ }^{c}$ School of Materials Science and Engineering, Harbin University of \\ Science and Technology, Harbin 150040, China \\ ${ }^{d}$ Shanghai Aircraft Manufacturing Co., Ltd., Shanghai 201324, China
}

Received: October 21, 2019; Revised: February 3, 2020; Accepted: March 18, 2020

(c) The Author(s) 2020.

\begin{abstract}
Hydroxyapatite (HA) bioceramic scaffolds were fabricated by using digital light processing (DLP) based additive manufacturing. Key issues on the HA bioceramic scaffolds, including dispersion, DLP fabrication, sintering, mechanical properties, and biocompatibility were discussed in detail. Firstly, the effects of dispersant dosage, solid loading, and sintering temperature were studied. The optimal dispersant dosage, solid loading, and sintering temperature were $2 \mathrm{wt} \%, 50 \mathrm{vol} \%$, and $1250{ }^{\circ} \mathrm{C}$, respectively. Then, the mechanical properties and biocompatibility of the HA bioceramic scaffolds were investigated. The DLP-prepared porous HA bioceramic scaffold was found to exhibit excellent mechanical properties and degradation behavior. From this study, DLP technique shows good potential for manufacturing HA bioceramic scaffolds.
\end{abstract}

Keywords: additive manufacturing; digital light processing; vat photopolymerization; hydroxyapatite; bioceramic scaffold

\section{Introduction}

Bioceramics have attracted great attentions in recent decades [1]. Among various bioceramics, hydroxyapatite (HA) is the most important major bioceramic which can be widely used in bone tissue engineering and bone defect repair, owing to its good biocompatibility

* Corresponding authors.

E-mail: R.He, herujie@bit.edu.cn;

C.Xie, tonyxiechen@163.com and bioactivity [2-4]. The excellent osteoconductivity makes HA as an artificial substitute material for bone, and also makes bone cells adhere, proliferate, and mineralize on surface. Usually, the scaffold used for bone tissue engineering and bone defect repairing is a porous structure for cell infiltration, angiogenesis, nutrient transport, and metabolic waste removal. Recently, various traditional manufacturing techniques have been used to fabricate porous HA bioceramic scaffolds, such as polymer sponge [5], freeze drying [6], gel casting [7], and so on. However, on the one 
hand, these traditional manufacturing techniques cannot control the porosity of the porous bioceramic scaffold accurately; on the other hand, these traditional techniques cannot achieve a complex-shaped bone scaffold. Therefore, it is deemed necessary to develop an advanced technique to manufacture the bioceramic scaffold.

Additive manufacturing (AM), usually called three dimensional (3D) printing, has undergone increasing development for ceramics in recent years [1,3,8-10]. $\mathrm{AM}$ is done by adding ceramic materials layer by layer, which greatly reduces the waste of raw materials, and can achieve near-net complex-shaped ceramics without machining. Moreover, the distinct advantage of AM is the ability to fabricate individualized implants by using computer modeling and to control the shape and pore structure of the bioceramic scaffold precisely [11]. Till now, there have been many additive manufacturing techniques reported to fabricate HA bioceramics, such as selective laser sintering (SLS), selective laser melting (SLM), fused deposition modelling (FDM), 3D printing (3DP), 3D gel-printing (3DGP), direct ink writing (DIW), and stereolithography (SLA). Tan et al. [12] prepared polyetheretherketone (PEEK)-HA biocomposite blends by using the SLS method. Hao et al. [13] obtained a stainless steel and HA composite for load-bearing implant development by using the SLM method. $\mathrm{Xu}$ et al. [14] fabricated 3D artificial polycaprolactone (PCL)-HA bones by the FDM technique. Wei et al. [15], Vorndarn et al. [16], and Brunello et al. [17] successfully prepared HA bioceramic bone scaffolds by using the $3 \mathrm{D}$ printing method. $\mathrm{Fu}$ et al. [18-20] also used 3D printing technique to prepare HA bioceramic, $\beta-\mathrm{Ca}_{2} \mathrm{SiO}_{4}$ bioceramic, and composite scaffolds for bone tissue engineering. Recently, Shao et al. [21] developed a novel 3DGP method to prepare HA scaffolds. Sun et al. [22], Shao et al. [23], and Simon et al. [24] also prepared HA bioceramic scaffolds by using the DIW technique. Most importantly, stereolithography based additive manufacturing has the advantages of low manufacturing cost, high-precision, and short cycle time, and has been widely employed to manufacture bioceramic parts. Stereolithography based additive manufacturing usually includes SLA and digital light processing (DLP). Among these, SLA can adapt to almost any ceramic powder and has been widely reported. Ronca et al. [25] successfully prepared poly(d,1-lactide)/nanosized HA biocomposite structures by the stereolithography method. Skoog et al. [26] and Wang et al. [27] also obtained HA bioceramics for bone tissue engineering. Lasgorceix et al. [28] developed a novel microstereolithography technique to prepare macro- micro-porous silicon substituted HA bioceramic. Recently, Chen et al. [29] also conducted a study on HA bioceramic prepared by the stereolithography technique. Besides, some other typical bioceramics, such as calcium phosphate (TCP) [30], have been fabricated by using the stereolithography based additive manufacturing. In contrast to SLA, DLP's ultraviolet light is projected to the bottom of the transparent storage tank by the projection equipment under the storage tank. The thickness of the fixed layer is maintained by controlling the distance between the molding table and the bottom of the storage tank and the ceramic body is formed after the curing. The ultraviolet (UV) beams of SLA scan layer by layer, so the molding speed is slow. However, DLP uses UV light to shape the shape of each molding section to the printing surface accurately, so the accuracy is higher and the molding speed is faster [31]. Therefore, DLP has a great advantage in manufacturing large parts with complex shape and high precision. Liu et al. [32] achieved hydroxyapatite bone scaffolds via DLP method and studied the in vitro compatibility. Zeng et al. [33] also prepared hydroxyapatite scaffolds with good mechanical and biocompatible properties by using the DLP method. In addition, other bioceramics, such as $\mathrm{CaP}$ bioceramic [34] and zirconia [35], have also been successfully prepared by using the DLP method. However, the influences of DLP conditions, including the dispersion, processing parameters, solid loading, and sintering temperature, have not been clearly completely analyzed. Intrinsic relationships among processing, microstructure, and properties during the DLP based additive manufacturing of HA bioceramic scaffolds are deemed necessary.

In this study, HA bioceramic scaffolds were prepared through DLP based additive manufacturing. Key issues on the DLP fabrication, including the dispersion, DLP process, sintering, mechanical properties, and biocompatibility of HA bioceramic scaffold were studied systematically. It is believed that this study can provide a comprehensive insight to the DLP based additive manufacturing of bioceramic scaffolds for bone tissue engineering and bone defect repair. 


\section{Experimental}

\section{1 Raw materials}

HA bioceramic scaffolds were fabricated by using DLP based additive manufacturing in this study. Commercial HA raw powders (laboratory reagent; Sinopharm Chemical Reagent Co., Ltd., China) were used as raw materials, as shown in Fig. 1. It was found that the HA raw powders were consisted of micron-sized particles and some nano-sized particles onto the surface of micron-sized particles. The average particle size of the micron-sized HA particles was about $8 \mu \mathrm{m}$, whereas the particle size of the micron-sized HA particles was only ranging from 100 to $200 \mathrm{~nm}$. For DLP, 1,6-hexanediol diacrylate (HDDA, Sinopharm Chemical Reagent Co., Ltd., China), 2-hydroxyethyl methacrylate (HEMA, Sinopharm Chemical Reagent Co., Ltd., China), and trimethylolpropane triacrylate (TMPTA, Sinopharm Chemical Reagent Co., Ltd., China) were used as resin monomers. The volume ratio of the HDDA-HEMA-TMPTA hybrid resin system is $6: 3: 1$. Free radical photoinitiator diphenyl(2,4,6-trimethylbenzoyl)phosphine oxide (TPO, Sinopharm Chemical Reagent Co., Ltd., China) was used as photoinitiator. Solsperse 17000 (Guangzhou Qian'an Chemical Co., Ltd., China) was used as dispersant.

\section{2 Dispersion of HA-resin slurry}

Firstly, HA particles and HDDA-HEMA-TMPTA monomers were weighed according to different solid loading (40 vol\%, $45 \mathrm{vol} \%$, and $50 \mathrm{vol} \%$ ), and then ball-milled for $6 \mathrm{~h}$ with zirconia ball media in a planetary mill (QM-3SP2, Nanjing University Instrument Plant, China) at $400 \mathrm{rpm}$. After that, TPO photoinitiator and Solsperse 17000 dispersant were added to the slurry and continued milling for $2 \mathrm{~h}$. The dosage of TPO was $1.5 \mathrm{wt} \%$ based on the weight of the resins,

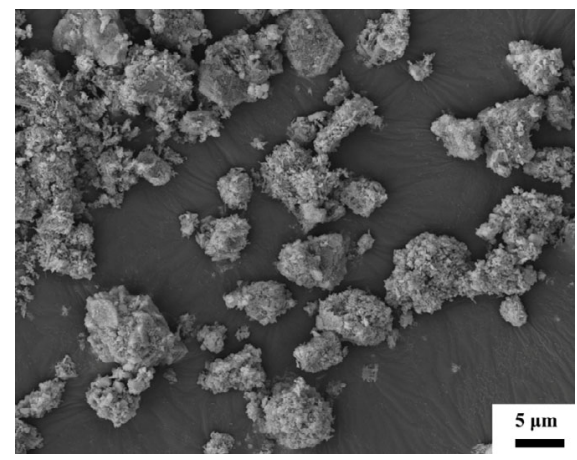

Fig. 1 SEM image of commercial HA raw powders. and the doping content of Solsperse 17000 was set as $1 \mathrm{wt} \%, 2 \mathrm{wt} \%$, and $3 \mathrm{wt} \%$ based on the powder weight, respectively. Finally, homogeneous dispersed HA-resin slurries with different solid loading were obtained for DLP fabrication.

\section{3 DLP of HA bioceramic scaffolds}

DLP fabrication was then conducted on the HA-resin slurry by using a commercial 3D printing equipment (AutoCera, Beijing 10dim Tech. Co., Ltd., China), as shown in Fig. 2. Firstly, a 3D model was imported into the equipment. The thickness for each slice layer for DLP was set as $25 \mu \mathrm{m}$. The slurry was poured into the tank, and homogeneously coated on a glass sheet using a blade. After that, the slurry was exposed to a UV light (wavelength: $405 \mathrm{~nm}$; intensity: $8000 \mu \mathrm{W} / \mathrm{cm}^{2}$; exposure time for the 1st layer: $35 \mathrm{~s}$; exposure time for each layer: $8 \mathrm{~s}$ ), and cross-linked to form a single layer. Then, the working stage was moved upwards and the slurry was re-coated on the sheet, continued to the solidification of the next layer. After such cycles, HA green bioceramic scaffolds were obtained.

\section{4 Sintering of HA scaffolds}

HA green scaffold was pyrolyzed at $650{ }^{\circ} \mathrm{C}$ in $\mathrm{N}_{2}$ atmosphere using a Muffle furnace (Hefei Facerom Furnace Co., Ltd., China) to burn out the polymers among the green body. The sample was firstly heated to $330{ }^{\circ} \mathrm{C}$ at a heating rate of $1{ }^{\circ} \mathrm{C} / \mathrm{min}$ and soaked for $60 \mathrm{~min}$, and then heated to $650{ }^{\circ} \mathrm{C}$ at a heating rate of $0.2{ }^{\circ} \mathrm{C} / \mathrm{min}$ and soaked for $120 \mathrm{~min}$. After binder removal, the HA ceramic scaffold was continued to be heated to the target sintering temperature at a heating rate of $0.5{ }^{\circ} \mathrm{C} / \mathrm{min}$ and soaked for $120 \mathrm{~min}$. In this study,

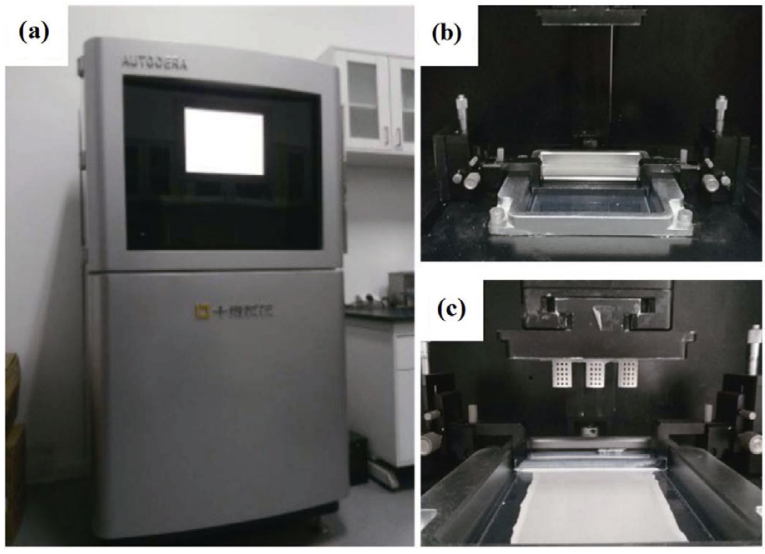

Fig. 2 (a) DLP equipment and (b, c) DLP fabrication of HA bioceramic scaffolds. 
the target sintering temperature was set as 1200,1250 , and $1300{ }^{\circ} \mathrm{C}$, respectively. Finally, the furnace was cooled to room temperature at a rate of $1{ }^{\circ} \mathrm{C} / \mathrm{min}$.

\section{5 Mechanical properties and biocompatibility of HA bioceramic scaffolds}

The green and sintered flexural strength of the HA bioceramics were measured via three-point bending tests based on $3 \mathrm{~mm} \times 4 \mathrm{~mm} \times 36 \mathrm{~mm}$ (wide $\times$ height $\times$ length) bars by a universal mechanical testing machine (Instron Legend 2367 testing system, USA), using a loading span of $30 \mathrm{~mm}$ with a crosshead speed of $0.5 \mathrm{~mm} / \mathrm{min}$ at room temperature. The green and sintered compression strength of the HA bioceramic were measured based on $\phi 5 \mathrm{~mm} \times 12.5 \mathrm{~mm}$ (diameter $\times$ height) cylinder with a crosshead speed of $0.05 \mathrm{~mm} / \mathrm{min}$ at room temperature. A minimum number of five specimens were tested to obtain an average value. For HA bioceramic scaffolds, the compression strength of the complex-shaped scaffold were measured with a crosshead speed of $0.05 \mathrm{~mm} / \mathrm{min}$ at room temperature.

In vitro tests of the HA bioceramic scaffolds were conducted in a Tris- $\mathrm{HCl}$ solution. Firstly, the HA scaffold was soaked in the Tris- $\mathrm{HCl}$ solution at $37{ }^{\circ} \mathrm{C}$. Then, the $\mathrm{pH}$ value was measured by using a $\mathrm{pH}$ meter after one, two, three, and four weeks soaking. Then, the HA scaffold was washed by using deionized water and anhydrous ethanol, dried in an electric oven at $60{ }^{\circ} \mathrm{C}$ for one day and weighted. The weight loss of the HA scaffold was calculated based on the mass before and after soaking.

\section{6 Other characterizations}

The viscosity of the HA-resin slurry was determined by using a rotational viscometer (NDJ-1B, Shanghai Pingxuan Instrument Co., Ltd., China). The rheological property of the HA-resin slurry was determined by using a rotational rheometer (MCR301, Anton Paar $\mathrm{GmbH}$, Germany). Binder removal behavior was determined by using a thermogravimetric and differential thermal analysis (TG-DTA 6200, Seiko, Japan) in $\mathrm{N}_{2}$ at a heating rate of $2{ }^{\circ} \mathrm{C} / \mathrm{min}$ up to $800{ }^{\circ} \mathrm{C}$. The relative density was measured by Archimedes method in deionized water. The crystalline phase of the ceramic after pyrolysis at different temperature was characterized using X-ray diffraction (XRD, Bruker D8 Advance, Germany). The microstructure was observed by using a scanning electron microscope (SEM, JSM-7500F, JEOL, Japan).

\section{Results and discussion}

\section{1 Dispersion of HA-resin slurry}

\subsubsection{Effects of dispersant dosage}

DLP fabrication is conducted upon the photopolymerization of the photosensitive ceramic-resin slurry, and therefore its dispersion and rheological behaviors are very important. In this study, the effects of dispersant dosage and solid loading on the dispersion and rheological behaviors of the HA-resin slurry were investigated. Figure 3(a) shows the effects of dispersant dosage on the viscosity of HA-resin slurry. The solid loading was kept as a constant of $45 \mathrm{vol} \%$, and the dosage of Solsperse 17000 dispersant was set as $1 \mathrm{wt} \%$, $2 \mathrm{wt} \%$, and $3 \mathrm{wt} \%$, respectively. As shown in Fig. 3(a), all HA-resin slurry exhibited pseudoplastic fluid and shear thinning features. When the dosage of Solsperse 17000 dispersant was $1 \mathrm{wt} \%$, both the viscosity at low and high shear rates were relatively higher than those of the slurries with $2 \mathrm{wt} \%$ and $3 \mathrm{wt} \%$ dispersant. The reason was attributed to that when the dispersant dosage was very small, HA bioceramic particles were not effectively modified by the dispersant. The collision of ceramic particles produced by Brownian motion caused the ceramic particles that had not adsorbed the dispersant to adhere and agglomerate, and therefore the stability of the HA-resin slurry was poor. When the dispersant dosage increased, the dosage was conducive to increase the coverage of the HA particle surface. The dispersant was easy to form a network structure in the slurry, which formed a layer of organic protective film on HA particle surface to prevent the particles from colliding with each other. Thus, a stable and well-dispersed HA-resin slurry was achieved. Nevertheless, the adsorption of HA particle surface reached saturation, while the dispersant dosage was too high, the excess and the free dispersant molecules would be in the inter-particle framework. According to the DLVO theory, the bridge caused flocculation, which degraded the stability of the system and then resulted in a viscosity increase of the HA-resin slurry. The absorption states of the dispersant onto HA particle surface were illustrated in Fig. 3(a). Therefore, when the dispersant dosage was $3 \mathrm{wt} \%$, the viscosity at low shear rates was higher than that of slurry with $1 \mathrm{wt} \%$ dispersant, whereas lower than that of slurry with $2 \mathrm{wt} \%$ dispersant. Because of the excessive dosage of dispersant (3 $\mathrm{wt} \%$ ), excessive long polymer chains 

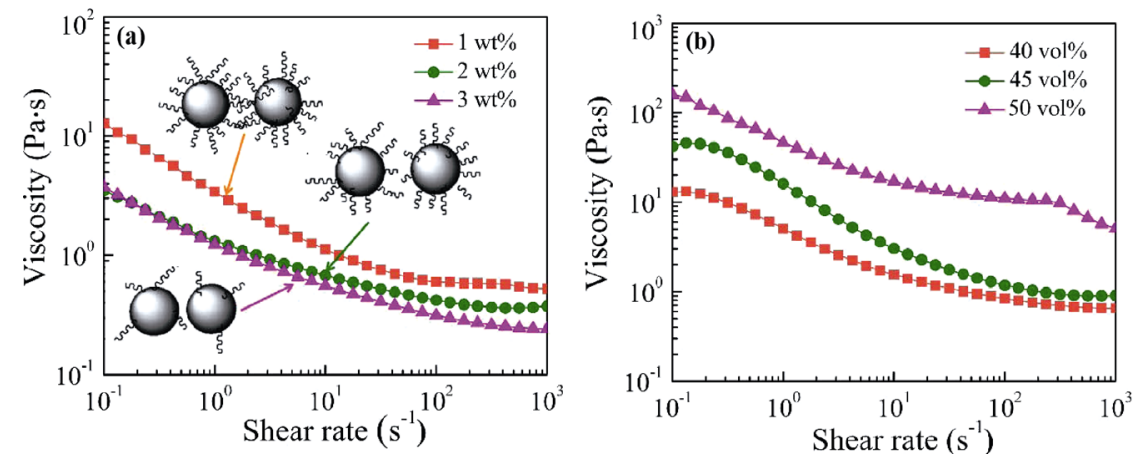

Fig. 3 (a) Effects of dispersant dosage on the viscosity of HA-resin slurry (solid loading: 45 vol\%) and (b) effects of solid loading on the viscosity of HA-resin slurry (dispersant dosage: $2 \mathrm{wt} \%$ ).

intertwined with each other and formed a hybrid polymer network, which needed a much higher force to open it, therefore resulted in a higher viscosity. With the shear rate increasing, the hybrid polymer network was opened; therefore, the viscosity of the slurry with $3 \mathrm{wt} \%$ dispersant was nearly the same as that of slurry with $2 \mathrm{wt} \%$ dispersant. However, when the shear rate was further increased, large shear centrifugal force caused some anchor bonding between ceramic particles and the dispersant polymers were broken, ceramic particles became to exhibit hydrophobicity and shear thinning behavior. Therefore, considering the viscosity and rheological behaviors, it seemed reasonable to say that the optimal dispersant dosage was $2 \mathrm{wt} \%$. Further investigation would be discussed based on the effects of solid loading in Section 3.1.2.

\subsubsection{Effects of solid loading}

After the dispersant dosage was chosen as $2 \mathrm{wt} \%$, the effects of solid loading on the viscosity of HA-resin slurry were further studied, as shown in Fig. 3(b). It is known that low solid loading will induce large shrinkage deformation, inevitable cracks, and defects during binder removal and sintering. Therefore, in order to achieve the highest relative density and mechanical properties, it is deemed necessary to achieve HA-resin slurry with the highest solid loading as well as best rheological behaviors as much as possible. In this study, the solid loading of the HA-resin slurry was set as $40 \mathrm{vol} \%, 45 \mathrm{vol} \%, 50 \mathrm{vol} \%$, respectively. From Fig. 3(b), it was obviously found that the viscosity order of the HA-resin slurry was: viscosity $(40 \mathrm{vol} \%)<$ viscosity $(45 \mathrm{vol} \%)<$ viscosity (50 vol\%). With the solid loading increasing, the number of ceramic particles among the slurry became more and thus the amount of resin became less. Therefore, the inner friction among the HA-resin slurry became larger, finally inducing the viscosity became larger. It was found that the slurry with a solid loading of $40 \mathrm{vol} \%$ was the optimal slurry for the following fabrication owing to its low viscosity. Therefore, how to choose the optimal solid loading of the HA-resin slurry needs to be further discussed considering its effects on strength and microstructure.

\section{2 DLP of HA bioceramic scaffolds}

HA bioceramic cuboid bars and scaffolds were DLP fabricated from HA-resin slurries with different solid loading. Figure 4(a) shows the typical 3D model of the HA bioceramic scaffold, and Fig. 4(b) shows the typical HA bioceramic green cuboid bar and scaffold. In addition, the green strength (flexural strength and compression strength) of the DLP-prepared HA green bioceramics were investigated. Detailed effects of Solsperse 17000 dispersant dosage and solid loading on green strength were discussed in detail.
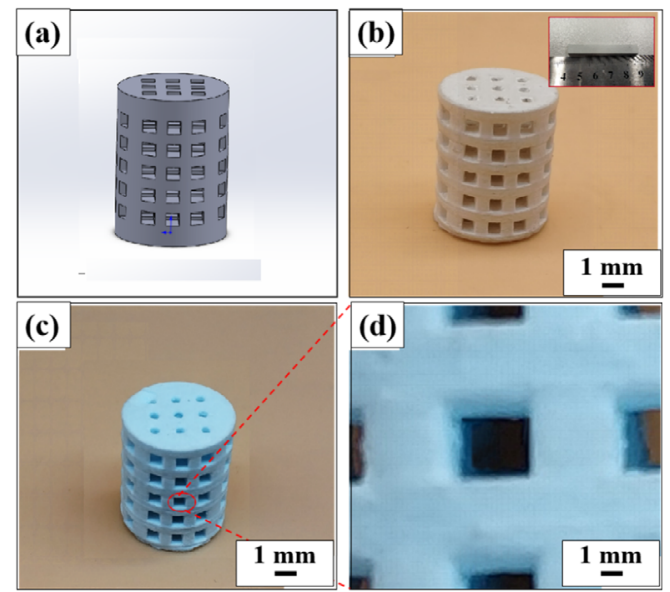

Fig. 4 Photographs of HA bioceramic scaffold: (a) 3D model, (b) green scaffold (inserted with green bar), and (c) sintered scaffold; (d) enlarged photo of (c). 


\subsubsection{Effects of dispersant dosage}

When the solid loading was set as a medium constant of $45 \mathrm{vol} \%$, the effects of dispersant dosage on green strength were shown in Fig. 5. It was found that both the green flexural strength and compression strength of the DLP-prepared HA green bioceramics increased firstly and then decreased with the dispersant dosage increasing. Both the green flexural strength and compression strength of the DLP-prepared HA green bioceramic had the highest value when the dispersant dosage was $2 \mathrm{wt} \%$. The highest green flexural strength and compression strength were measured to be 27.8 and $161.9 \mathrm{MPa}$, respectively. The green strength was high enough to conduct the following transportation and sintering. Therefore, the optimal dispersant dosage of the HA-resin slurry could be chosen as $2 \mathrm{wt} \%$.

\subsubsection{Effects of solid loading}

After determining the optimal dispersant dosage was $2 \mathrm{wt} \%$, the effects of solid loading of HA-resin slurry on the green flexural strength and compression strength were further discussed, as shown in Fig. 6. The green flexural strength of the HA green bioceramic from 40 vol $\%, 45 \mathrm{vol} \%$, and 50 vol $\%$ slurries was $36.5,27.8$, and 25.4 MPa, respectively, as shown in Fig. 6(a). With the solid loading increasing, the green strength of the HA green bodies decreased correspondingly. The phenomena highly agreed with the results of the effects of solid loading on the viscosity of HA-resin slurry shown in Fig. 3. It was found that a slurry with high solid loading exhibited high viscosity. High viscosity usually induced worse dispersion of the HA-resin slurry, more defects during DLP process, and less homogeneous microstructure of the HA green bioceramic after DLP process. The green compression strength of the HA green bioceramic from $40 \mathrm{vol} \%, 45$ vol $\%$, and 50 vol $\%$ slurries was $144.6,161.9$, and 145.5 MPa, respectively, as shown in Fig. 6(b). With the solid loading increasing, the green compression strength increased firstly and then decreased. With the solid loading increasing, the pressure-resistant solid particles among the green body became more and thus the compression strength increased. However, with the solid loading further increased, the homogeneous behavior of the green body became worse and thus the compression strength decreased instead. The highest compression strength of $161.9 \mathrm{MPa}$ was obtained when the solid loading was $45 \mathrm{vol} \%$. It seemed that the solid loading of the HA-resin slurry was chosen as $45 \mathrm{vol} \%$.
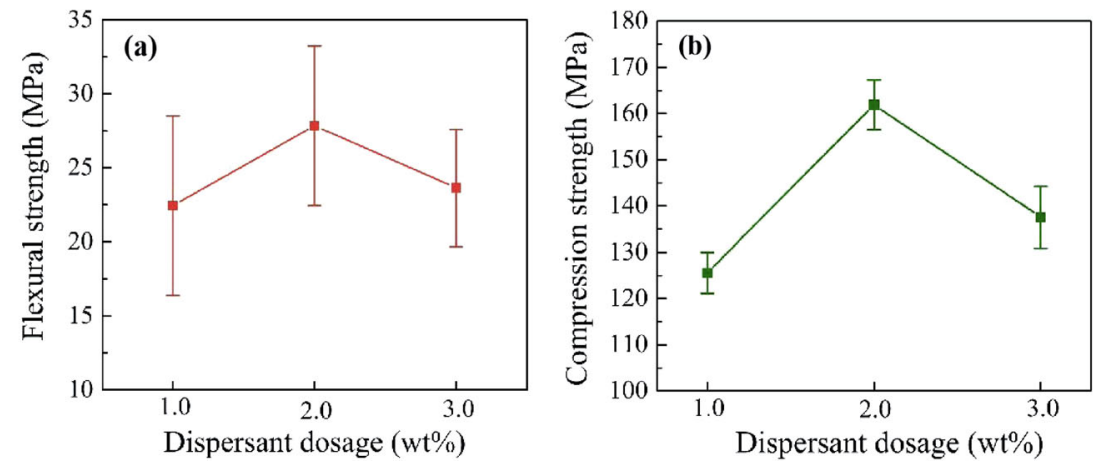

Fig. 5 Effects of dispersant dosage on (a) flexural strength and (b) compression strength of HA green bioceramics (solid loading: $45 \mathrm{vol} \%$ ).
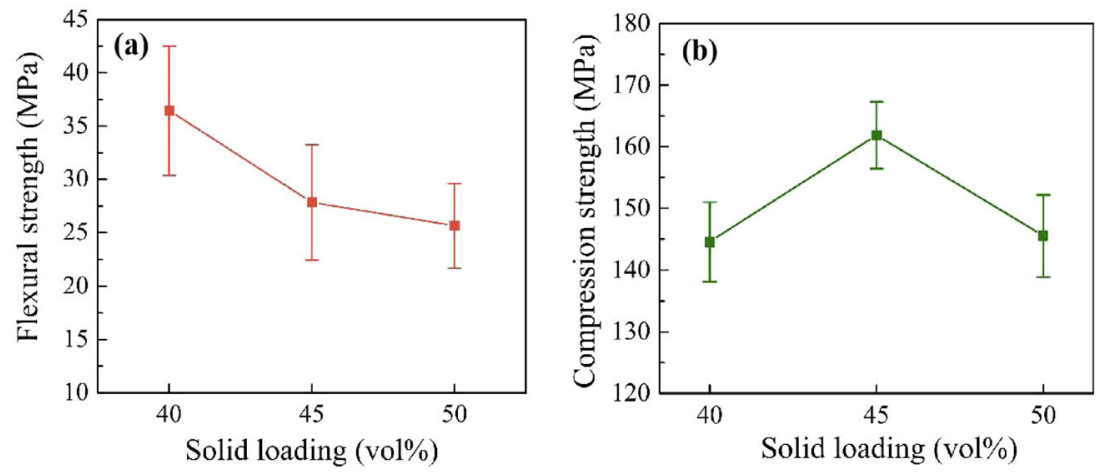

Fig. 6 Effects of solid loading on (a) flexural strength and (b) compression strength of HA green bioceramics (dispersant dosage: $2 \mathrm{wt} \%$ ). 


\section{3 Sintering of HA bioceramic scaffolds}

\subsubsection{Sintering program}

In order to obtain HA bioceramic scaffold, polymers among green body, including resin and dispersant, must be burnt out firstly. Compared to traditional colloidal processing techniques, the polymers among HA-resin slurry was much more, resulting in more complex binder removal behavior. DTA-TG analysis from room temperature to $800{ }^{\circ} \mathrm{C}$ was used to evaluate the polymer burn-out behavior of the HA green bioceramic, as shown in Fig. 7(a). Interestingly, it was found that there was only one main large weight loss peak for TG curve even the resin system was composed of HEMA-HDDA-TMPTA composite resin monomers. The reason for the phenomena was supposed to the nearly same chemical composition and the similar molecular structure of these three types of resin monomers. Before $330{ }^{\circ} \mathrm{C}$, a very small weight loss rate of $2.59 \%$ was observed, mainly attributing to the volatilization of low oiling point small molecules among the system, such as molecular water and un-cross-linked resin monomers. When the temperature was above $330{ }^{\circ} \mathrm{C}$, the weight loss rate exponential increased and the resin was burnt out quickly, which resulted in an obvious exothermic peak of the DTA curve. Violent thermal decomposition nearly completed when the temperature was up to $480{ }^{\circ} \mathrm{C}$, at which the weight loss rate was as high as $96.26 \%$. When the temperature was further increased, the TG curve became gentle and the weight loss became very small. Due to the violent thermal decomposition and large weight loss between 330 and $480{ }^{\circ} \mathrm{C}$, it must be noted that the sintering protocol should be carefully controlled at a very slow heating rate in order to avoid defects and cracks, which mainly inducing by the larger inner stress because of the large number of gases during binder removal. There was about $2 \%$ weight

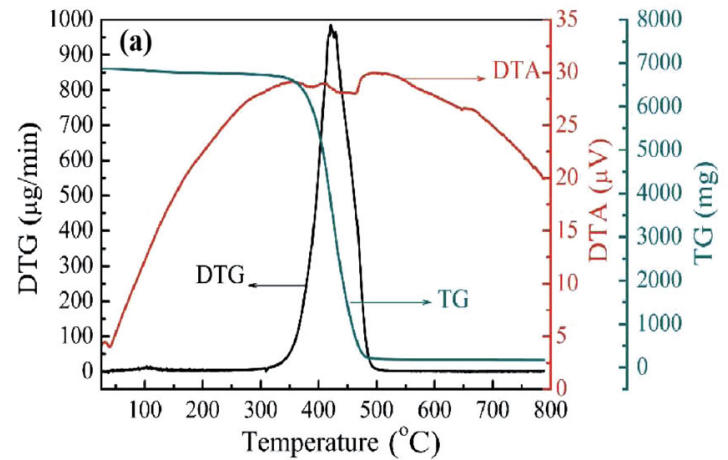

loss of the TG curve and a bit of small exothermic peaks of the DTA curve between 480 and $650{ }^{\circ} \mathrm{C}$, owing to the thermal decomposition of some macromolecular groups with a high crosslinking degree. After that, the TG curve became horizontal and there was no more decomposition reaction happened.

Therefore, the sintering protocol of the DLP-prepared HA bioceramic scaffold was given in Fig. 7(b). HA green scaffold was pyrolyzed at $650{ }^{\circ} \mathrm{C}$ in $\mathrm{N}_{2}$ atmosphere to burn out the polymers among the green body. The sample was firstly heated to $330{ }^{\circ} \mathrm{C}$ at a heating rate of $1{ }^{\circ} \mathrm{C} / \mathrm{min}$ and soaked for $60 \mathrm{~min}$, and then heated to $650{ }^{\circ} \mathrm{C}$ at a heating rate of $0.2{ }^{\circ} \mathrm{C} / \mathrm{min}$ and soaked for $120 \mathrm{~min}$. After the binder removal, the HA bioceramic scaffold was continued to be heated to the target sintering temperature at a heating rate of $0.5{ }^{\circ} \mathrm{C} / \mathrm{min}$ and soaked for $120 \mathrm{~min}$. In our study, the target sintering temperature was set as 1200,1250 , and $1300{ }^{\circ} \mathrm{C}$, respectively. Finally, the furnace was cooled to room temperature at a rate of $1{ }^{\circ} \mathrm{C} / \mathrm{min}$.

\subsubsection{Effects of solid loading}

The effects of solid loading and sintering temperature were discussed in detail. Firstly, it is widely reported that the shrinkage rate in $X, Y$, and $Z$ directions exhibits a small difference during the stereolithography based additive manufacturing of photosensitive resins [36,37] and/or ceramics [38,39]. In our previous study [40], we also reported the different shrinkage in different directions during the stereolithography based additive manufacturing of $\mathrm{ZrO}_{2}$ ceramic. Usually, it should be noticed that the shrinkage difference in different direction is very small, but many researchers ignored this shrinkage difference and proposed an average shrinkage value in their papers. In this study, we also adopted the average shrinkage rate value for HA bioceramics. Table 1 lists the relative density, average shrinkage rate, flexural strength, and compression

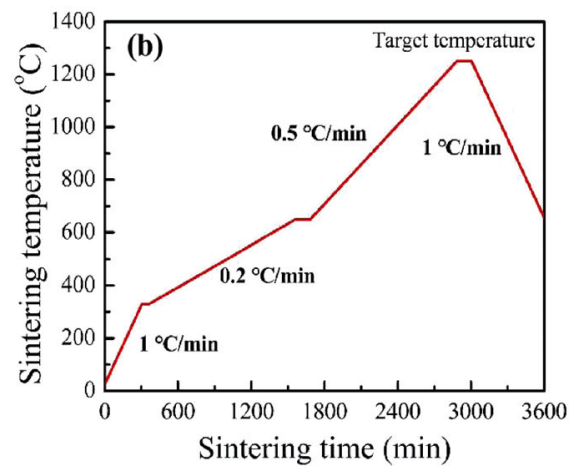

Fig. 7 (a) DTA-TG curves of the HA green bioceramic and (b) sintering program of the DLP-prepared HA bioceramic scaffold. 
Table 1 Relative density, average shrinkage rate, flexural strength, and compression strength of the sintered HA bioceramics

\begin{tabular}{|c|c|c|c|c|}
\hline \multirow{2}{*}{$\begin{array}{c}\text { Solid } \\
\text { loading } \\
\text { (vol\%) }\end{array}$} & \multirow{2}{*}{ Property } & \multicolumn{3}{|c|}{ Sintering temperature $\left({ }^{\circ} \mathrm{C}\right)$} \\
\hline & & 1200 & 1250 & 1300 \\
\hline \multirow{4}{*}{40} & Relative density (\%) & $63.5 \pm 1.3$ & $69.7 \pm 2.9$ & $76.3 \pm 1.2$ \\
\hline & Average shrinkage rate $(\%)$ & $18.7 \pm 0.9$ & $19.6 \pm 0.9$ & $21.6 \pm 1.4$ \\
\hline & Flexural strength (MPa) & $7.5 \pm 1.6$ & $9.8 \pm 2.2$ & $5.8 \pm 2.5$ \\
\hline & Compression strength $(\mathrm{MPa})$ & $9.3 \pm 4.4$ & $13.0 \pm 3.3$ & $14.5 \pm 4.2$ \\
\hline \multirow{4}{*}{45} & Relative density (\%) & $66.6 \pm 1.3$ & $73.0 \pm 3.1$ & $78.1 \pm 1.5$ \\
\hline & Average shrinkage rate $(\%)$ & $17.2 \pm 1.3$ & $17.6 \pm 1.4$ & $19.4 \pm 1.3$ \\
\hline & Flexural strength (MPa) & $10.0 \pm 2.8$ & $13.7 \pm 2.4$ & $7.8 \pm 3.0$ \\
\hline & Compression strength $(\mathrm{MPa})$ & $12.0 \pm 4.6$ & $15.9 \pm 3.7$ & $21.4 \pm 5.1$ \\
\hline \multirow{4}{*}{50} & Relative density (\%) & $68.3 \pm 1.8$ & $74.6 \pm 1.5$ & $78.8 \pm 1.6$ \\
\hline & Average shrinkage rate $(\%)$ & $14.8 \pm 1.1$ & $15.3 \pm 0.7$ & $16.5 \pm 0.3$ \\
\hline & Flexural strength (MPa) & $12.9 \pm 2.1$ & $18.3 \pm 2.5$ & $12.1 \pm 4.0$ \\
\hline & Compression strength (MPa) & $12.5 \pm 7.5$ & $16.9 \pm 6.8$ & $18.1 \pm 7.1$ \\
\hline
\end{tabular}

strength of the sintered HA bioceramics.

The sintering temperature was firstly set as $1200{ }^{\circ} \mathrm{C}$, and the effects of solid loading on relative density, average shrinkage rate, flexural strength, and compression strength of the sintered HA bioceramics were studied, as shown in Fig. 8. Figure 8(a) presents the effects of solid loading on the relative density and average shrinkage rate of the HA bioceramics. When the sintering temperature was $1200{ }^{\circ} \mathrm{C}$, the relative density of the HA bioceramics from $40 \mathrm{vol} \%, 45 \mathrm{vol} \%$, and $50 \mathrm{vol} \%$ solid loading was $63.5 \%, 66.6 \%$, and $68.3 \%$, respectively, which were suitable for following medical application $[41,42]$. The shrinkage rate of the
HA bioceramics from $40 \mathrm{vol} \%, 45 \mathrm{vol} \%$, and $50 \mathrm{vol} \%$ solid loading was $18.7 \%, 17.2 \%$, and $14.8 \%$, respectively. It was found that the relative density increased and the shrinkage decreased with the solid loading increasing. The amount of ceramic particles among the slurry became more with the solid loading increasing, and therefore the relative density of the HA bioceramics increased correspondingly and the shrinkage decreased instead. Figure 8(b) further shows the effects of solid loading on the flexural strength and compression strength of the HA bioceramics. The flexural strength of the HA bioceramics from $40 \mathrm{vol} \%, 45 \mathrm{vol} \%$, and 50 vol\% solid loading were $7.5,10.0$, and $12.9 \mathrm{MPa}$, respectively. And the compression strength of the HA bioceramics from $40 \mathrm{vol} \%, 45 \mathrm{vol} \%$, and $50 \mathrm{vol} \%$ solid loading was $9.3,12.0$, and $12.5 \mathrm{MPa}$, respectively. It was clearly found that the flexural strength and compression strength of the HA bioceramics increased with the solid loading increasing, which could be also attributed to the relative density increasing trend with the solid loading increasing. The reasons for these results could be further identified by microstructure observation. Figure 9 shows the SEM images of the bioceramics from slurries with different solid loading. With the solid loading increasing, the solid ceramic particles became more, and thus the pores became less. Therefore, the relative density, flexural strength, and compression strength increased, and the shrinkage rate therefore decreased correspondingly. In order to apply the HA bioceramics to clinical applications, the strength should be enough to surgery; hence, the optimal solid loading of the HA-resin slurry should be chosen as $50 \mathrm{vol} \%$.
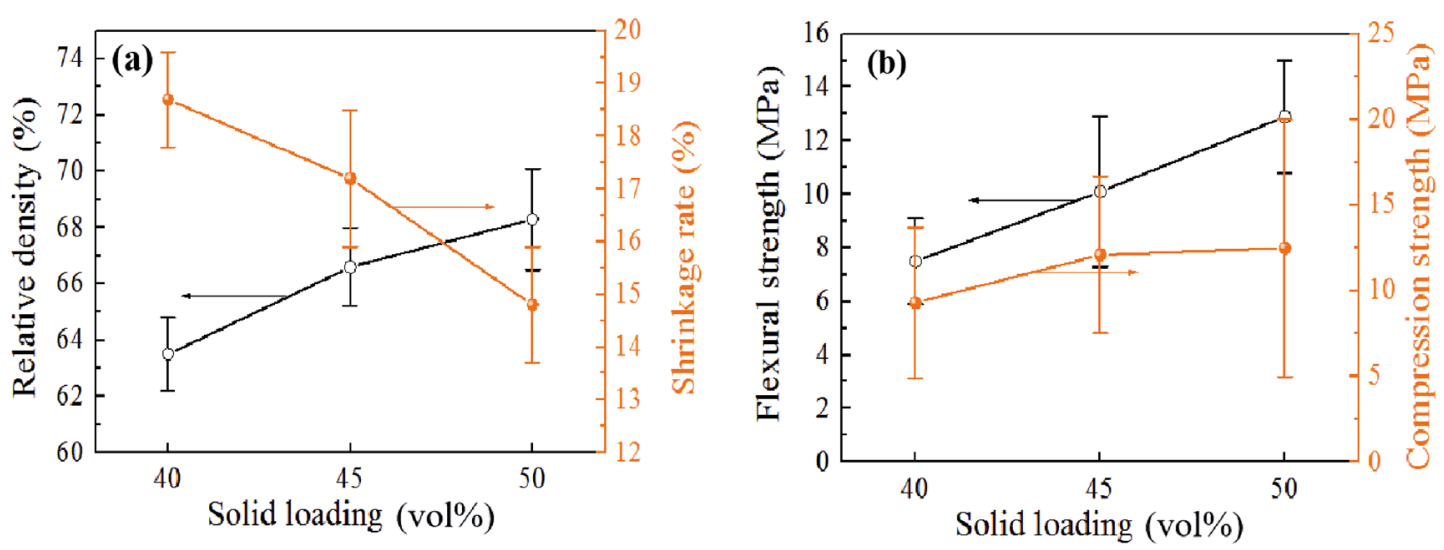

Fig. 8 Effects of solid loading on (a) relative density and average shrinkage rate and (b) flexural strength and compression strength (sintering temperature: $1200{ }^{\circ} \mathrm{C}$ ). 

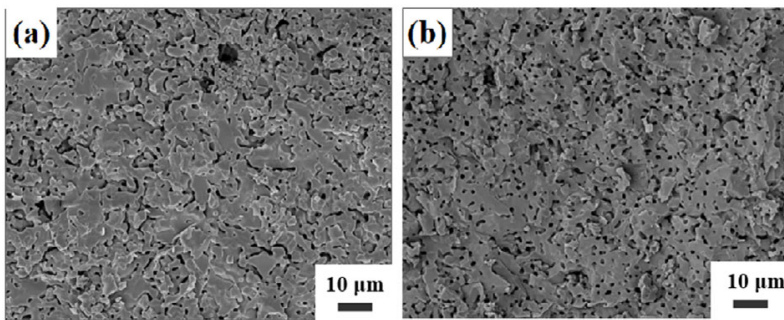

(c)
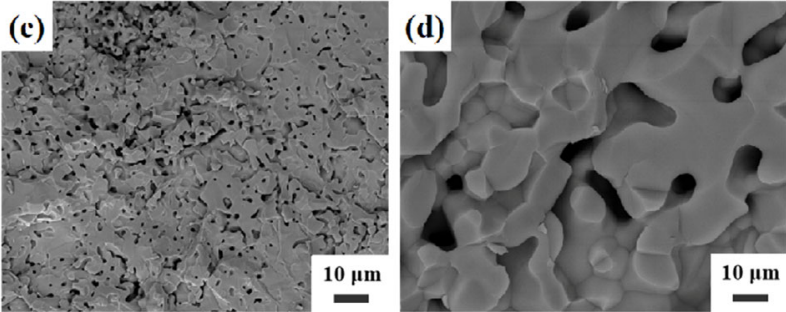

Fig. 9 SEM images of the HA bioceramics sintered at $1200{ }^{\circ} \mathrm{C}$ : (a) $40 \mathrm{vol} \%$, (b) $45 \mathrm{vol} \%$, and (c) $50 \mathrm{vol} \%$; (d) high magnification of (c).

\subsubsection{Effects of sintering temperature}

Figure 10 shows the effects of sintering temperature on relative density, shrinkage rate, flexural strength, and compression strength of the sintered bioceramics when the solid loading was set as $50 \mathrm{vol} \%$. As shown in Fig. 10(a), the relative density and shrinkage rate increased with the sintering temperature increasing. It was attributed to that the ceramic particles became more aggregated and the ceramic became much denser when the sintering temperature was increased. Figure 11 shows the SEM images of the sintered HA bioceramics sintered at different temperatures. It was observed that the number of pores among the ceramic decreased with the sintering temperature increasing, and the microstructure became denser correspondingly. The microstructure observation results were in good agreement with the relative density results shown in Fig. 10. The flexural strength firstly increased then decreased with the sintering temperature increasing, whereas the compression strength always increased with the sintering temperature increasing (Fig. 10(b)). Detailed reasons for these results can be further discussed by XRD analysis about the phase changes during sintering process.

The effects of sintering temperature on the phase compositions and phase changes were thus discussed. Except for the target sintering temperature, the raw material and the $\mathrm{HA}$ bioceramic sintered at $800{ }^{\circ} \mathrm{C}$ were also investigated. Figure 12 shows the XRD patterns of raw HA powders and HA bioceramics sintered at different temperatures $(800,1200,1250$, and $1300{ }^{\circ} \mathrm{C}$ ). For raw powders, there were only
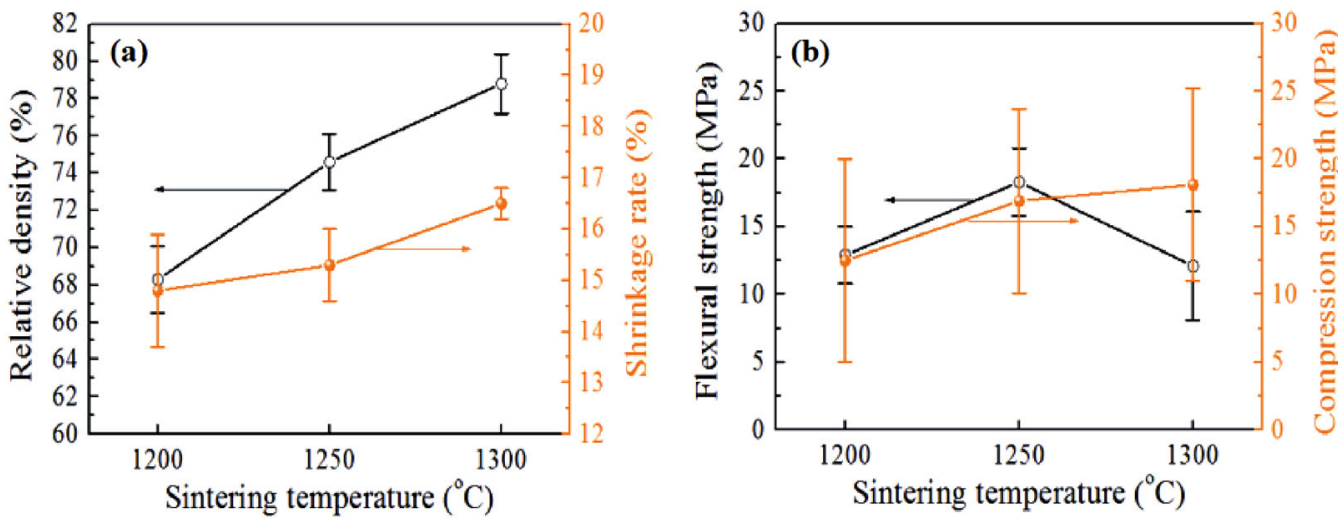

Fig. 10 Effects of sintering temperature on (a) relative density and shrinkage rate and (b) flexural strength and compression strength (solid loading: $50 \mathrm{vol} \%$ ).
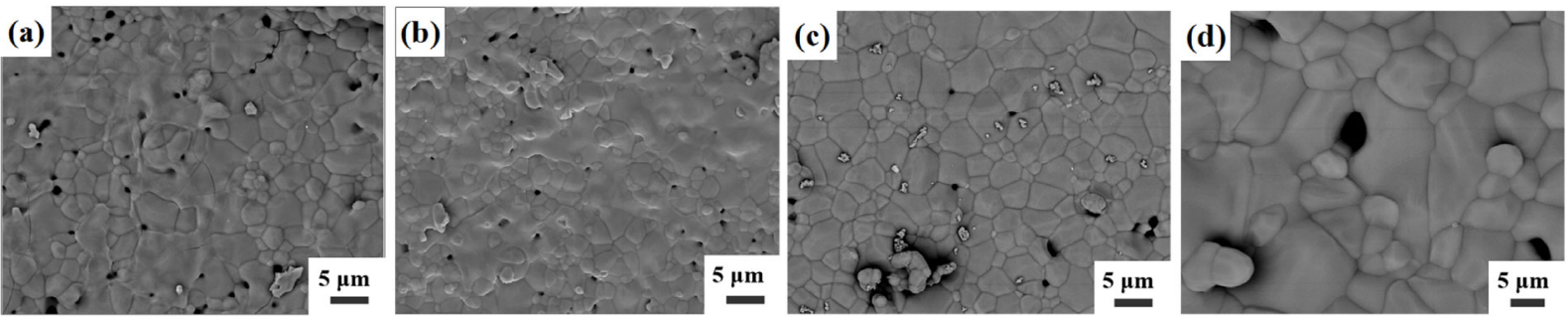

Fig. 11 SEM images of the HA bioceramics (solid loading: 50 vol\%): (a) $1200{ }^{\circ} \mathrm{C}$, (b) $1250{ }^{\circ} \mathrm{C}$, and (c) $1300{ }^{\circ} \mathrm{C}$; (d) high magnification of (c). 


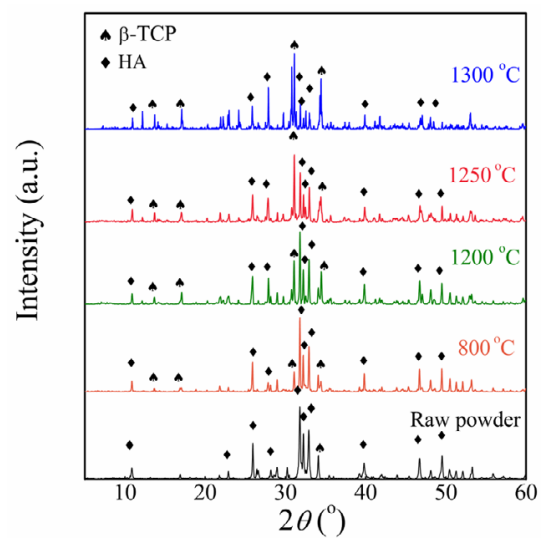

Fig. 12 XRD patterns of raw HA powders and HA bioceramics.

characteristic peaks for HA observed from the XRD pattern. Usually, synthesis of pure stoichiometric (the mole ratio of $\mathrm{Ca}$ atom and $\mathrm{P}$ atom, $\mathrm{Ca} / \mathrm{P}=10 / 6) \mathrm{HA}$ powders is very difficult and challenging, and there is always a trace amount of inevitable non-stoichiometric $(\mathrm{Ca} / \mathrm{P}<10 / 6)$ HA powders existed. However, the trace amount of non-stoichiometric HA phase did not be detected in the XRD patterns. For HA bioceramic sintered at $800{ }^{\circ} \mathrm{C}$, it was found that there were relatively weak $\beta$-TCP peaks, indicating that the phase change from HA to TCP occurred. It was attributed to the thermal induced phase change from non-stoichiometric $(\mathrm{Ca} / \mathrm{P}<10 / 6)$ HA phase into $\beta$-TCP phase, which resulted in the exothermic peaks in Fig. 7(a).

$$
\begin{gathered}
\mathrm{Ca}_{10-x} \mathrm{H}_{2 x}\left(\mathrm{PO}_{4}\right)_{6}(\mathrm{OH})_{2} \stackrel{800{ }^{\circ} \mathrm{C}}{\longrightarrow} \\
\beta-\mathrm{Ca}_{3}\left(\mathrm{PO}_{4}\right)_{2}+\mathrm{Ca}_{10}\left(\mathrm{PO}_{4}\right)_{2}
\end{gathered}
$$

With the heating temperature further increased (1200, 1250 , and $1300{ }^{\circ} \mathrm{C}$ ), the peak shapes of $\beta$-TCP phase became sharper, and the absorption peak intensity became higher. This phenomenon indicated that the amount of the phase-changed $\beta$-TCP became more with the temperature increasing. At higher temperatures, a dehydration decomposition reaction for stoichiometric HA bioceramic might happen.

$$
\begin{gathered}
\mathrm{Ca}_{10}\left(\mathrm{PO}_{4}\right)_{6}(\mathrm{OH})_{2} \stackrel{>1050^{\circ} \mathrm{C}}{\longrightarrow} \\
\underset{2 \beta-\mathrm{Ca}_{3}\left(\mathrm{PO}_{4}\right)_{2}+\mathrm{Ca}_{4} \mathrm{P}_{2} \mathrm{O}_{9}}{\longrightarrow}
\end{gathered}
$$

Actually, non-stoichiometric HA bioceramic, usually known as calcium-deficient hydroxyapatite (CDHA), which is also a kind of ceramic very similar to stoichiometric HA bioceramic, exhibits excellent biocompatibility and osteoinductive properties. Both stoichiometric and non-stoichiometric HA bioceramics are suitable biological bone materials. Moreover, the mixture of HA and $\beta$-TCP was always called biphasic calcium phosphate bioceramics. It was reported that the biphasic calcium phosphate had an excellent combination of mechanical, biocompatibility, and osteoinductive properties [43].

As shown in Fig. 10(b), the flexural strength of the HA bioceramics sintered at 1200,1250 , and $1300{ }^{\circ} \mathrm{C}$ were $12.9,18.3$, and $12.1 \mathrm{MPa}$, respectively. The flexural strength firstly increased and then decreased with the sintering temperature increasing. This was because the densification became more obvious when the sintering temperature increased from 1200 to $1250{ }^{\circ} \mathrm{C}$; however, the phase change reactions also became more obvious when the sintering temperature was further increased (Fig. 12). Usually, phase change results in inevitable cracks owing to the thermal expansion coefficient mismatch between the HA phase and $\beta$-TCP phase. Figure 13 demonstrates the typical cracks existed in the HA bioceramic sintered at $1300{ }^{\circ} \mathrm{C}$. There were obvious cracks between particles, even among particles. These cracks resulted in the decreasing trend of the flexural strength. It should be noted that the compression strength was less affected by cracks. The compression strength of the HA bioceramics sintered at 1200,1250 , and $1300{ }^{\circ} \mathrm{C}$ were $12.5,16.9$, and $18.1 \mathrm{MPa}$, respectively. The compression strength increased with the sintering temperature increasing owing to that the relative density was increasing correspondingly. Considering the flexural strength and compression strength simultaneously, the optimal sintering temperature was chosen as $1250{ }^{\circ} \mathrm{C}$ in this study.

\section{4 Mechanical properties and biocompatibility of HA bioceramic scaffolds}

In this study, HA bioceramic scaffolds were finally manufactured by using DLP technique. Figure 4(a) shows the $3 \mathrm{D}$ model for HA bioceramic scaffold. A helical micrometer was used to measure the directional dimensions (height, diameter, and lattice pore size of the porous scaffold structure) of the DLP-prepared HA bioceramic scaffolds from different solid loading slurries, as listed in Table 2. The designed height,
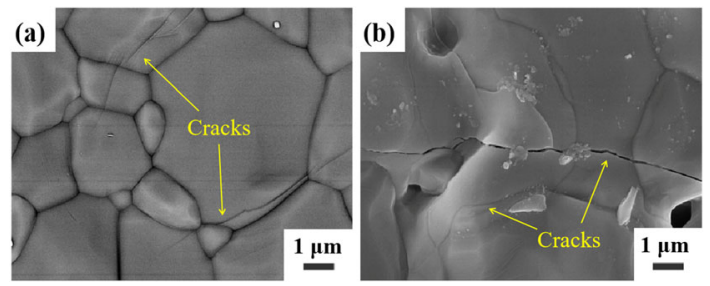

Fig. 13 SEM images of HA bioceramic sintered at $1300{ }^{\circ} \mathrm{C}$ (solid loading: $50 \mathrm{vol} \%$ ): (a, b) cracks at different locations. 
Table 2 Directional dimensions of the HA bioceramic scaffolds

\begin{tabular}{cccc}
\hline $\begin{array}{c}\text { Solid loading } \\
(\text { vol\%) }\end{array}$ & $\begin{array}{c}\text { Height } \\
(\mathrm{mm})\end{array}$ & $\begin{array}{c}\text { Diameter } \\
(\mathrm{mm})\end{array}$ & $\begin{array}{c}\text { Lattice pore size } \\
(\mathrm{mm})\end{array}$ \\
\hline 40 & 14.5 & 12.1 & 1.21 \\
45 & 14.2 & 11.8 & 1.17 \\
50 & 13.8 & 11.5 & 1.15 \\
Product geometry & 12.0 & 10.0 & 1.0 \\
\hline
\end{tabular}

diameter, and pore size of the scaffold was kept as 12.0, 10.0 , and $1.0 \mathrm{~mm}$, respectively. The height, diameter, and pore size values of the HA bioceramic scaffolds were in good agreement with the shrinkage rate results shown in Figs. 8 and 10. The HA bioceramic scaffold prepared from 50 vol\% solid loading slurry exhibited the best shape-maintaining ability, which further induced that the optimal solid loading of the HA-resin slurry was 50 vol\%. In addition, Figs. 4(c) and 4(d) show the optical microscopy of sintered HA bioceramic scaffold, and it was observed that the DLP-prepared HA bioceramic scaffold maintains high manufacturing accuracy and quality. DLP technique showed excellent potential application for the fabrication of bioceramic scaffolds.

\subsubsection{Mechanical properties of HA bioceramic scaffolds}

One of the most important indexes to evaluate the performance of the HA bioceramic scaffold is mechanical property, especially the compression property. The compression strength of the HA bioceramic scaffold was measured with a crosshead speed of $0.05 \mathrm{~mm} / \mathrm{min}$ at room temperature. In this study, the total porosity is the sum of the microstructural porosity of the HA bioceramic and the lattice porosity of the scaffold structure. Table 3 lists the total porosity and compression strength of the DLP-prepared HA bioceramic scaffolds from different solid loading slurries. Owing to the different relative densities of the HA bioceramics, the total porosity, considering the material's porosity and structural porosity, was measured and calculated. The total porosity of the HA bioceramics scaffold from 40 vol $\%, 45 \mathrm{vol} \%$, and $50 \mathrm{vol} \%$ solid loading slurries was $54.52 \%, 52.41 \%$, and $49.32 \%$, respectively. The changing trends fitted very well with the material's relative density results and designed porosity. Figure 14 shows the compression strength-compression strain curves of the HA bioceramic scaffolds from different solid loading slurries. The maximum load at break was used for calculation of compression strength for each condition. Therefore, the compression strength of the HA bioceramic scaffolds from $40 \mathrm{vol} \%, 45 \mathrm{vol} \%$, and $50 \mathrm{vol} \%$ solid loading slurries were $1.45,1.76$, and $1.92 \mathrm{MPa}$, respectively (Table 3 ). References [41,42] showed that the porous bioceramic scaffolds with the compression strength ranges were suitable for medical application. Besides, the compression strength value of the DLP-prepared HA bioceramic scaffolds was nearly the same as that of human cancellous bone ( 1.9 MPa) [44], indicating the DLP-prepared HA bioceramic scaffolds having excellent clinical usage potential. During compression, typical compression failure models, including brittle fracture and fragmentation, occurred. Figure 15(a) presents the deformation history of the HA bioceramic scaffold under compression loading. There were four typical stages showing the failure mechanism of the bioceramic scaffold under compression, as illustrated in Fig. 15(b): ( I ) Compression: the scaffold became dense under axial compressive loading, and the compression load reached the first peak value; ( II ) Expansion: the waist part of the scaffold was expanded, the compression load decreased slowly, and then the load became increasing once again; (III) Shear: after the load reached the maximum value, shear and brittle fracture happened, and the scaffold was crushed; (IV) Collapse: the scaffold was crushed into fragments, and the load decreased. The HA bioceramic scaffold exhibited a similar strength- and loading-conditioned behaviors of bone tissue for practical clinical application.

Table 3 Total porosity and compression strength of the $\mathrm{HA}$ bioceramic scaffolds sintered at $1250{ }^{\circ} \mathrm{C}$

\begin{tabular}{ccc}
\hline Solid loading (vol\%) & Total porosity (\%) & Compression strength (MPa) \\
\hline 40 & $54.52 \pm 4.91$ & $1.45 \pm 0.26$ \\
45 & $52.41 \pm 2.97$ & $1.76 \pm 0.36$ \\
50 & $49.32 \pm 2.96$ & $1.92 \pm 0.31$ \\
\hline
\end{tabular}

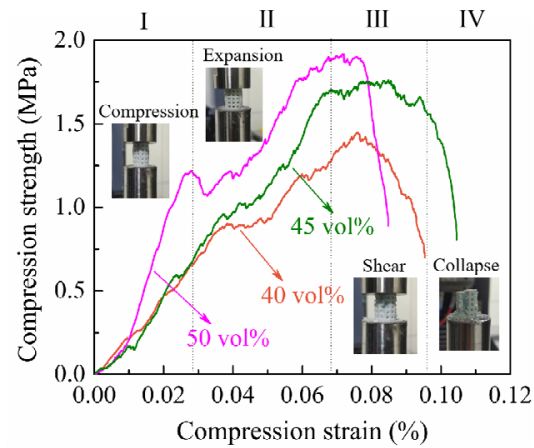

Fig. 14 Compression strength-strain curves of the HA bioceramic scaffolds sintered at $1250{ }^{\circ} \mathrm{C}$. 
(a)

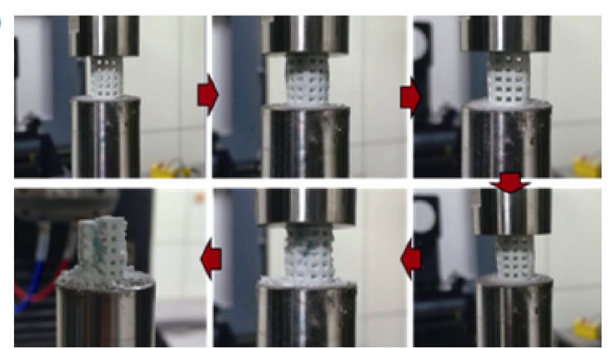

(b)

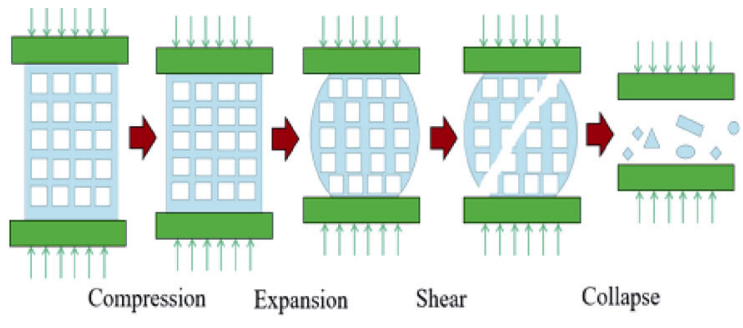

Fig. 15 (a) Deformation history and (b) failure mechanism of the HA bioceramic scaffold under compression loading.

\subsubsection{Biocompatibility of scaffolds}

One of the other most important indexes to evaluate the performance of the HA bioceramic scaffold is biocompatibility. In this study, the in vitro behavior of the DLP-prepared HA bioceramic scaffolds were evaluated by testing the $\mathrm{pH}$ value change of the Tris-HCl solution for different soaking time. The $\mathrm{pH}$ value change of the Tris- $\mathrm{HCl}$ solution was given in Fig. 16. The $\mathrm{pH}$ value of the raw Tris- $\mathrm{HCl}$ solution was 7.5. After the HA bioceramic scaffolds soaking in the solution for different weeks, the $\mathrm{pH}$ value changes of the solution were detected. With the soaking time increasing, the $\mathrm{pH}$ value of the solution increased correspondingly. The $\mathrm{pH}$ value reached 8.2 after threeweek soaking. However, the $\mathrm{pH}$ values kept almost the same from three to four weeks $(\sim 8.2)$. The reason was attributed to the chelation effect of $\mathrm{PO}_{4}^{3-}$ with $\mathrm{H}^{+}$ during HA dissolution in the Tris- $\mathrm{HCl}$ solution, which was also reported by Shao et al. [21]. The weight loss values of the HA ceramic scaffolds for different soaking time were also given in Fig. 16. After soaking for one and two weeks, the weight loss of the HA ceramic scaffolds increased significantly, and the weight loss value reached $11.2 \%$ after two-week soaking. The weight loss values kept as almost the same from three to four weeks $(\sim 11.9 \%-12.2 \%)$, which was in good agreement with the $\mathrm{pH}$ value results, and the weight loss value was $12.2 \%$ after four-week soaking. It was known that porous HA bioceramic exhibited some kind of degradable behavior, and the weight loss of the porous HA bioceramic scaffold increased with the soaking time increasing. During the corrosion process in the Tris- $\mathrm{HCl}$ solution, the calcium and phosphorus ions on the surface of HA bioceramic dissolved and exchanged with the ions in the resolution to achieve an equilibrium state. As the degradation and ion exchange processing, the ions inside the HA bioceramic gradually participate in the reactions. The

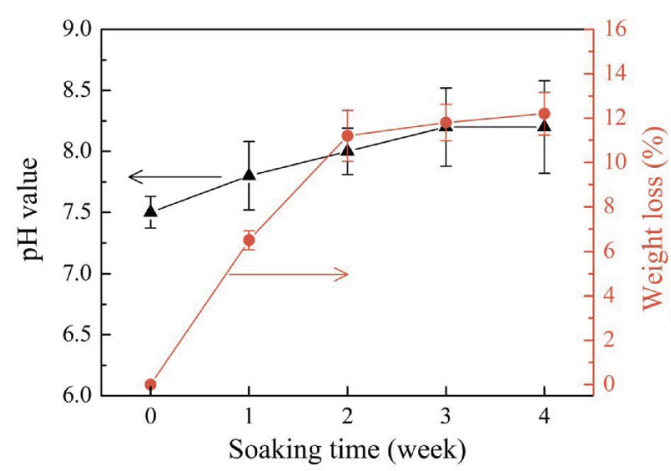

Fig. $16 \mathrm{pH}$ value change of the Tris- $\mathrm{HCl}$ solution and weight loss of the HA ceramic scaffolds.

degradation rate of the porous HA bioceramic scaffold was firstly fast and then slow. At last, the weight loss increased and finally became stable. As known, an appropriate degradation rate can maintain the initial mechanical properties of the porous HA bioceramic scaffold, and exhibit enough time for the growth of bone cells. Therefore, the weight loss of the porous HA bioceramic scaffold exhibited excellent degradation behavior and showed good potential for bone tissue engineering.

\section{Conclusions}

In this study, HA bioceramic scaffolds were prepared by using DLP based additive manufacturing technique. The dispersion of the HA-resin slurry, the DLP fabrication procedure, the sintering of the HA bioceramic scaffold, and the mechanical properties and biocompatibility of HA bioceramic scaffold were studied and discussed. Solsperse 17000 was used as the dispersant, and high dispersed HA-resin slurry was obtained. The optimal dispersant dosage and solid loading were chosen as $2 \mathrm{wt} \%$ and $50 \mathrm{vol} \%$, respectively. HA bioceramic scaffolds were manufactured by using DLP technique from different solid loading slurry. The DLP-prepared HA bioceramic scaffold maintained 
high manufacturing accuracy and quality. The sintering of the HA bioceramic scaffold was studied. The optimal solid loading and sintering temperature were set as $50 \mathrm{vol} \%$ and $1250{ }^{\circ} \mathrm{C}$, respectively. The mechanical properties and biocompatibility of the HA bioceramic scaffolds were studied. Both the compression strength and the degradation behavior showed that the HA bioceramic scaffolds had good potential for bone tissue engineering. In summary, the DLP based additive manufacturing technique can be used for the fabrication of HA bioceramic scaffolds, and the DLP-prepared HA bioceramic scaffolds show excellent clinical potential for bone tissue engineering. It should be noted that more detailed investigation on the fabrication and biocompatibility, especially in vivo and in vitro tests should be conducted systematically in the future.

\section{Acknowledgements}

This study is mainly financially supported by the Beijing Natural Science Foundation (2182064) hosted by Prof. Rujie He. Prof. Rujie He also thanks the support from the National Natural Science Foundation of China (51772028). Prof. Min Xia thanks the support from the Fundamental Research Funds for the Central Universities (3052017010). Prof. Xinxin Jin thanks the support from the National Natural Science Foundation of China (51602082). Dr. Keqiang Zhang thanks the support from the Graduate Technology Innovation Project of Beijing Institute of Technology (No. 2019CX10020).

\section{References}

[1] Fu SY, Zhu M, Zhu YF. Organosilicon polymer-derived ceramics: An overview. J Adv Ceram 2019, 8: 457-478.

[2] Wu Z, Zhou ZR, Hong YL. Isotropic freeze casting of through-porous hydroxyapatite ceramics. $J$ Adv Ceram 2019, 8: 256-264.

[3] Witek L, Shi Y, Smay J. Controlling calcium and phosphate ion release of 3D printed bioactive ceramic scaffolds: An in vitro study. J Adv Ceram 2017, 6: 157-164.

[4] Shen TT, Yang WH, Shen XK, et al. Polydopamineassisted hydroxyapatite and lactoferrin multilayer on titanium for regulating bone balance and enhancing antibacterial property. ACS Biomater Sci Eng 2018, 4: 3211-3223.

[5] Ramay HR, Zhang MQ. Preparation of porous hydroxyapatite scaffolds by combination of the gel-casting and polymer sponge methods. Biomaterials 2003, 24: 3293-3302.
[6] Lee EJ, Koh YH, Yoon $\mathrm{BH}$, et al. Highly porous hydroxyapatite bioceramics with interconnected pore channels using camphene-based freeze casting. Mater Lett 2007, 61: 2270-2273.

[7] Yang TY, Lee JM, Yoon SY, et al. Hydroxyapatite scaffolds processed using a TBA-based freeze-gel casting/polymer sponge technique. J Mater Sci: Mater Med 2010, 21: 1495-1502.

[8] Yan S, Huang YF, Zhao DK, et al. 3D printing of nano-scale $\mathrm{Al}_{2} \mathrm{O}_{3}-\mathrm{ZrO}_{2}$ eutectic ceramic: Principle analysis and process optimization of pores. Addit Manuf 2019, 28: 120-126.

[9] Chen ZW, Li ZY, Li JJ, et al. 3D printing of ceramics: A review. J Eur Ceram Soc 2019, 39: 661-687.

[10] Cheng ZL, Ye F, Liu YS, et al. Mechanical and dielectric properties of porous and wave-transparent $\mathrm{Si}_{3} \mathrm{~N}_{4}-\mathrm{Si}_{3} \mathrm{~N}_{4}$ composite ceramics fabricated by $3 \mathrm{D}$ printing combined with chemical vapor infiltration. $J A d v$ Ceram 2019, 8: 399-407.

[11] Du XY, Fu SY, Zhu YF. 3D printing of ceramic-based scaffolds for bone tissue engineering: An overview. $J$ Mater Chem B 2018, 6: 4397-4412.

[12] Tan KH, Chua CK, Leong KF, et al. Scaffold development using selective laser sintering of polyetheretherketonehydroxyapatite biocomposite blends. Biomaterials 2003, 24: 3115-3123.

[13] Hao L, Dadbakhsh S, Seaman O, et al. Selective laser melting of a stainless steel and hydroxyapatite composite for load-bearing implant development. $J$ Mater Process Technol 2009, 209: 5793-5801.

[14] Xu N, Ye XJ, Wei DX, et al. 3D artificial bones for bone repair prepared by computed tomography-guided fused deposition modeling for bone repair. ACS Appl Mater Interfaces 2014, 6: 14952-14963.

[15] Wei QH, Wang YN, Chai WH, et al. Molecular dynamics simulation and experimental study of the bonding properties of polymer binders in $3 \mathrm{D}$ powder printed hydroxyapatite bioceramic bone scaffolds. Ceram Int 2017, 43: 13702-13709.

[16] Vorndran E, Moseke C, Gbureck U. 3D printing of ceramic implants. MRS Bull 2015, 40: 127-136.

[17] Brunello G, Sivolella S, Meneghello R, et al. Powder-based 3D printing for bone tissue engineering. Biotechnol Adv 2016, 34: 740-753.

[18] Fu SY, Hu HR, Chen JJ, et al. Silicone resin derived larnite/C scaffolds via 3D printing for potential tumor therapy and bone regeneration. Chem Eng $J$ 2020, 382: 122928.

[19] Fu SY, Yu B, Ding HF, et al. Zirconia incorporation in 3D printed $\beta-\mathrm{Ca}_{2} \mathrm{SiO}_{4}$ scaffolds on their physicochemical and biological property. J Inorg Mater 2019, 34: 444.

[20] Du XY, Wei DX, Huang L, et al. 3D printing of mesoporous bioactive glass/silk fibroin composite scaffolds for bone tissue engineering. Mater Sci Eng: C 2019, 103: 109731.

[21] Shao HP, He JZ, Lin $\mathrm{T}$, et al. 3D gel-printing of 
hydroxyapatite scaffold for bone tissue engineering. Ceram Int 2019, 45: 1163-1170.

[22] Sun L, Parker ST, Syoji D, et al. Direct-write assembly of 3D silk/hydroxyapatite scaffolds for bone Co-cultures. $A d v$ Healthc Mater 2012, 1: 729-735.

[23] Shao HF, Yang XY, He Y, et al. Bioactive glass-reinforced bioceramic ink writing scaffolds: Sintering, microstructure and mechanical behavior. Biofabrication 2015, 7: 035010.

[24] Simon JL, Michna S, Lewis JA, et al. In vivo bone response to $3 \mathrm{D}$ periodic hydroxyapatite scaffolds assembled by direct ink writing. J Biomed Mater Res 2007, 83A: 747-758.

[25] Ronca A, Ambrosio L, Grijpma DW. Preparation of designed poly(d,1-lactide)/nanosized hydroxyapatite composite structures by stereolithography. Acta Biomater 2013, 9: 5989-5996.

[26] Skoog SA, Goering PL, Narayan RJ. Stereolithography in tissue engineering. J Mater Sci: Mater Med 2014, 25 : 845-856.

[27] Wang Z, Huang CZ, Wang J, et al. Development of a novel aqueous hydroxyapatite suspension for stereolithography applied to bone tissue engineering. Ceram Int 2019, 45: 3902-3909.

[28] Lasgorceix M, Champion E, Chartier T. Shaping by microstereolithography and sintering of macro-microporous silicon substituted hydroxyapatite. J Eur Ceram Soc 2016, 36: 1091-1101.

[29] Chen QH, Zou B, Lai QG, et al. A study on biosafety of HAP ceramic prepared by SLA-3D printing technology directly. J Mech Behav Biomed Mater 2019, 98: 327-335.

[30] Putlyaev VI, Evdokimov PV, Safronova TV, et al. Fabrication of osteoconductive $\mathrm{Ca}_{3-x} \mathrm{M}_{2 x}\left(\mathrm{PO}_{4}\right)_{2}(\mathrm{M}=\mathrm{Na}, \mathrm{K})$ calcium phosphate bioceramics by stereolithographic $3 \mathrm{D}$ printing. Inorg Mater 2017, 53: 529-535.

[31] Wang M, Xie C, He RJ, et al. Polymer-derived silicon nitride ceramics by digital light processing based additive manufacturing. J Am Ceram Soc 2019, 102: 5117-5126.

[32] Liu ZB, Liang HX, Shi TS, et al. Additive manufacturing of hydroxyapatite bone scaffolds via digital light processing and in vitro compatibility. Ceram Int 2019, 45: 11079-11086.

[33] Zeng Y, Yan YZ, Yan HF, et al. 3D printing of hydroxyapatite scaffolds with good mechanical and biocompatible properties by digital light processing. $J$ Mater Sci 2018, 53: 6291-6301.

[34] Lee YH, Lee JB, Maeng WY, et al. Photocurable ceramic slurry using solid camphor as novel diluent for conventional digital light processing (DLP) process. $J$ Eur
Ceram Soc 2019, 39: 4358-4365.

[35] He RX, Liu W, Wu ZW, et al. Fabrication of complexshaped zirconia ceramic parts via a DLP- stereolithography-based 3D printing method. Ceram Int 2018, 44: 3412-3416.

[36] Karalekas D, Aggelopoulos A. Study of shrinkage strains in a stereolithography cured acrylic photopolymer resin. $J$ Mater Process Technol 2003, 136: 146-150.

[37] Wang WL, Cheah CM, Fuh JYH, et al. Influence of process parameters on stereolithography part shrinkage. Mater Des 1996, 17: 205-213.

[38] Xing HY, Zou B, Li SS, et al. Study on surface quality, precision and mechanical properties of $3 \mathrm{D}$ printed $\mathrm{ZrO}_{2}$ ceramic components by laser scanning stereolithography. Ceram Int 2017, 43: 16340-16347.

[39] Schwentenwein M, Homa J. Additive manufacturing of dense alumina ceramics. Int J Appl Ceram Technol 2015, 12: $1-7$.

[40] Zhang KQ, He RJ, Ding GJ, et al. Digital light processing of 3 Y-TZP strengthened $\mathrm{ZrO}_{2}$ ceramics. Mater Sci Eng: A 2020, 774: 138768.

[41] Qu HW, Fu HY, Han ZY, et al. Biomaterials for bone tissue engineering scaffolds: A review. $R S C A d v$ 2019, 9: 26252-26262.

[42] Yang YW, Wang GY, Liang HX, et al. Additive manufacturing of bone scaffolds. Int J Bioprint 2019, 5: 148-172.

[43] Lin SJ, LeGeros RZ, Rohanizadeh R, et al. Biphasic calcium phosphate (BCP) bioceramics: Preparation and properties. Key Eng Mater 2003, 240-242: 473-476.

[44] Zhao HX, Liang WH. A novel comby scaffold with improved mechanical strength for bone tissue engineering. Mater Lett 2017, 194: 220-223.

Open Access This article is licensed under a Creative Commons Attribution 4.0 International License, which permits use, sharing, adaptation, distribution and reproduction in any medium or format, as long as you give appropriate credit to the original author(s) and the source, provide a link to the Creative Commons licence, and indicate if changes were made.

The images or other third party material in this article are included in the article's Creative Commons licence, unless indicated otherwise in a credit line to the material. If material is not included in the article's Creative Commons licence and your intended use is not permitted by statutory regulation or exceeds the permitted use, you will need to obtain permission directly from the copyright holder.

To view a copy of this licence, visit http://creativecommons. org/licenses/by/4.0/. 